\title{
High thoracic epidural analgesia supplement seems to protect renal function, evaluated by serum creatinine changes, in cardiac surgery patients - a randomised study
}

\author{
Jacob Greisen, Dorthe Viemose Nielsen, Pia Katarina Ryhammer, Erik Sloth and Carl-Johan Jakobsen* \\ *Correspondence: cjj@dadlnet.dk \\ Department of Anaesthesiology and Intensive Care, Aarhus University Hospital, Skejby, Denmark.
}

\begin{abstract}
Acute kidney injury (AKI) after cardiac surgery is associated with increased mortality and morbidity. The AKI criteria used in the study is a slight modification ( 72 hours instead of 48 hours) of the consensus report from the Acute Kidney Injury Network. AKI is defined as an abrupt increase in s- creatinine $>26.5 \mu \mathrm{mol} / \mathrm{L}(0.3 \mathrm{mg} / \mathrm{dL})$, or a relative increase in s-creatinine $>50 \%$, or a decrease in urine output to $<0.5 \mathrm{ml} / \mathrm{kg} / \mathrm{h}$ for more than $6 \mathrm{~h}$ within the first postoperative day. We recently found that high thoracic epidural analgesia (HTEA) was associated with a decreased frequency of postoperative dialysis. The purpose of this study was to evaluate TEA on renal function expressed as postoperative changes in s-creatinine, with the hypothesis that HTEA improves renal function. Sixty low to moderate risk patients scheduled for elective coronary artery bypass grafting with or without aortic valve replacement were randomised to receive HTEA as supplement to general anaesthesia (GA).

Results: Serum-creatinine was lower in HTEA patients in the first 72 hours after surgery ( $\mathrm{P}=0.018,2$-way ANOVA), with overall maximal increase $12.1 \%$ vs. $23.8 \%$. The incidence of AKI was, although not significantly, lower (13.3\% vs. $36.7 \%, \mathrm{P}=0.074, \chi 2$-test). Use of inotropes, constrictors and vasodilators had no impact on development of AKI.

Conclusion: HTEA as a supplement to GA in cardiac surgery is followed by a less increase in s-creatinine in the first 72 hours after surgery and a tendency towards lower incidence of AKI. The finding of a possibly kidney-protective effect of HTEA could be of clinical importance and warrants further investigation.
\end{abstract}

Keywords: Acute kidney injury, high thoracic epidural analgesia, haemodynamics, constrictors

\section{Introduction}

Acute kidney injury (AKI) after cardiac surgery is associated with increased short and long term mortality and morbidity and renders the patients prone to longer hospitalisation and to higher costs during hospital stay. During the last decades there has been a continuous interest in fast-track cardiac anaesthesia protocols with the potential of increased quality of recovery and protective measures for negative outcomes like AKI, myocardial infarction and stroke [1-6]. The high thoracic epidural analgesia (HTEA) has gained increasing attention among anaesthesiologists and cardiac surgeons as a possibly protective treatment [7-10].

However; the beneficial effects of HTEA on clinical outcomes are still under debate as most trials are inadequately powered to draw firm conclusions regarding effect on mortality and major complications. A recent meta-analysis of randomised trials suggested a reduction in AKI in patients receiving HTEA together with a reduction in the composite endpoint of myocardial infarction and/or death [8]. We recently found a decrease in 6 month mortality after cardiac surgery with HTEA compared to a matched group of patients with no HTEA [11], where a regression analysis revealed that HTEA was the only factor with independent positive effect on the frequency of postoperative dialysis. Following we have made a follow-up study based on data from a previous published randomised study demonstrating improved haemodynamics after HTEA in cardiac surgery [12]. Localised impaired renal blood flow is most likely a major etiological factor for developing AKI. Based on recent studies [11-12] we speculated that that whole-body flow (cardiac output) seems more important than perfusion pressure over the kidney. The purpose of this present study was to evaluate HTEA as a supplement to GA on renal function expressed as postoperative changes in s-creatinine in cardiac surgery patients, with the hypothesis that HTEA improves renal function, by merging data from previously published RCT (12) with clinical laboratory data.

\section{Material and methods}

Sixty patients with a mean age 71 years (65-80), scheduled for elective coronary artery bypass grafting (CABG), aortic valve replacement (AVR) or combined surgery were included and randomised. The study was approved by the Central Denmark Region Committee on Biomedical Research Ethics and Danish Medicine Agency (EudraCT 2005-000617-35) and was carried out in accordance with the Helsinki II declaration. Sixty-three patients were approached of which two declined and one was excluded as surgery was changed to OPCAB. All AVR was due to aortic stenosis without regurgitation. Patients with ejection fraction below 0.3, myocardial infarction within the last four weeks, diabetes, severe pulmonary or arterial hypertension, 
preoperative antiplatelet and anticoagulation therapy contraindicating HTEA and patients without preoperative optimal echocardiographic imaging were excluded. The study was a follow up of previous published study [12] after merging study data with longitudinal data of s-creatinine and focusing on renal function.

All cardiac patients were routinely hospitalised the day before surgery. Written informed consent was obtained from all patients by a research nurse and preoperative echocardiography was performed. Randomisation by the standard envelope method was done immediately before insertion of epidural catheter the day before surgery. Patients were randomised to high thoracic epidural analgesia (HTEA group) or no HTEA (control group).

\section{High thoracic epidural analgesia}

The day before surgery, a $18 \mathrm{G}$ Portex ${ }^{\circledR}$ epidural catheter (Sims Portex Ltd., Kent UK) was inserted $3-4 \mathrm{~cm}$ into the epidural space through a Tuohy needle (Sims Portex Ltd.) via the second or third thoracic $\left(\mathrm{Th}_{2}-\mathrm{Th}_{4}\right)$ vertebral interspace. On arrival at the operating room an infusion of Ringers acetate was started through a peripheral venous line and was running until start of cardiopulmonary bypass (CPB). A test dose of $3 \mathrm{ml}$ of $2 \%$ Lidocaine was given epidurally to exclude the displacement of the catheter in the subarachnoid space or in a vessel. Five minutes later, a bolus dose of $5-7 \mathrm{ml}$, guided by primary patient heights, $0.5 \%$ Bupivacaine (Marcaine ${ }^{\circledR}$, Astra, Södertalje, Sweden) together with Sufentanil $2.5 \mu \mathrm{g} / \mathrm{ml}$ was given epidurally. The sensory blockade was not evaluated before continuing anaesthesia. After start of surgery the blockade was continued with a mixture of Bupivacaine $2.5 \mathrm{mg} / \mathrm{ml} /$ Sufentanil $1 \mu \mathrm{g} / \mathrm{ml} 4-6 \mathrm{ml} /$ hours, by discretion of the attending anaesthesiologist, until end of surgery. Shortly after arrival in ICU the epidural mixture was changed to Bupivacain $1 \mathrm{mg} / \mathrm{ml}$ together with Sufentanil $1 \mu \mathrm{g} / \mathrm{ml}$ and continued after discharge from the ICU until the second postoperative day.

\section{Anaesthesia and hemodynamic monitoring protocols} All preoperative cardiac medication was continued until the morning of surgery, with the exception of angiotensinconverting enzyme inhibitors, aspirin and platelet function inhibitors. All patients received standard oral premedication consisting of benzodiazepine 5-10 mg together with paracetamol 2g, 60-90 minutes before surgery. Anaesthesia consisted of either total intravenous anaesthesia using Propofol or Sevoflurane inhalation anaesthesia together with Sufentanil and Rocuronium $0.6 \mathrm{mg} / \mathrm{kg}$ for tracheal intubation. Standard monitoring included five-lead ECG, invasive radial arterial blood pressure, pulmonary artery catheter with continuous cardiac output measurement and end diastolic volume estimation and central venous oxygenation (CCO/ VIP catheter: 744 HF75; Edwards Lifesciences, Irvine, CA, USA), pulse oximetry, capnography and temperature monitoring. All hemodynamic and monitoring data were automatically saved in our patient data monitoring system every minute. Following all artefact values were removed and data were stored with 5 minute intervals for analysis.

\section{Hemodynamic control and guidance}

Primary parameters for control of perioperative haemodynamics were mean arterial pressure (MAP), cardiac index $(\mathrm{Cl})$ and central venous oxygenation $\left(\mathrm{SvO}_{2}\right)$. Perioperatively, the goal of MAP was to be kept between 60 and $90 \mathrm{mmHg}$. Low MAP was primarily treated by colloid infusion (Hydroxyethyl starch) and secondly noradrenaline infusion. Hypertension was treated primarily with Nitroprusside. Cardiac performance was guided by $\mathrm{Cl}$ intended to behigher than $2.0 \mathrm{~L} / \mathrm{m} 2$ and a $\mathrm{SvO}_{2}$ higher than $60 \%$. Before initiating inotropic therapy patients were evaluated by transoesophageal (peroperative) or transthoracic (postoperative) echocardiography to exclude volume depletion or signs of tamponade. Low heart rate was primarily treated by a pacemaker while high HR was not treated directly but managed by treating underlying conditions such as hypovolaemia. All decisions on volume and medical therapy were done by discretion of attending anaesthesiologist and intensivist based on protocol targets.

\section{Surgical procedure}

Routine surgical techniques and cardio-protective strategies using crystalloid cardioplegia together with closed cardiopulmonary bypass (CPB) systems were used in all patients. The CPB system consisted of tubing with a surface modifying additive coating, an arterial filter with heparin coating, a hollow fibred membrane oxygenator with a surface-modified additive coating and a venous and cardiotomy reservoir. Patients were kept normothermic. Weaning from CPB reperfusion of the heart was performed according to the patient's general condition and cross clamp time. There was no fixed postoperative treatment regimen for either pharmaceutical or mechanical support.

\section{Measurements and outcome}

We did not perform a power analysis for this substudy, but a post hoc analysis suggest that with this number of patients we had adequate power to identify a $10 \%$ difference in maximal postoperative change in s-creatinine.

Primary endpoints were relative changes in s-creatinine measured daily from the dayof surgery until discharge from hospital, compared to pre-operative obtained values. The changes in s-creatinine were further correlated to changes in haemodynamics and total fluid balances.

Secondary endpoints were acute kidney injury defined as an abrupt (within 72 hours) increase in s- creatinine $>26.5$ $\mu \mathrm{mol} / \mathrm{L}(0.3 \mathrm{mg} / \mathrm{dL})$, or a relative increase in serum creatinine $>$ $50 \%$, or a decrease in urine output to less than $0.5 \mathrm{ml} / \mathrm{kg} \mathrm{h}$ for more than $6 \mathrm{~h}$ within the first postoperative day. This definition of AKI is a slight modification of the consensus report from the Acute Kidney Injury Network (AKIN) [13] increasing the 
Greisen et al. Cardiovascular System 2013,

http://www.hoajonline.com/journals/pdf/2052-4358-1-11.pdf

doi: $10.7243 / 2052-4358-1-11$

Table 1. Preoperative demographics, cardiac medications, cardiac function evaluated by echocardiography and selected per-operative variables.

\begin{tabular}{|c|c|c|c|}
\hline $\begin{array}{l}\text { Preoperative } \\
\text { demographic data }\end{array}$ & Control & HTEA & $p$-value \\
\hline No of patients & 30 & 30 & -- \\
\hline Age (Yrs.) & $71.6 \pm 4.5$ & $70.9 \pm 4.6$ & 0.55 \\
\hline Body Mass Index (kg/m²) & $26.3 \pm 3.9$ & $26.1 \pm 2.8$ & 0.82 \\
\hline $\mathrm{s}$-creatinine $(\mathrm{mmol} / \mathrm{L})$ & $78.6 \pm 24.3$ & $79.7 \pm 18.1$ & 0.84 \\
\hline Creatinine clearance & $84.3 \pm 26.5$ & $79.2 \pm 23.4$ & 0.43 \\
\hline EuroSCORE & $5.4 \pm 2.1$ & $5.0 \pm 1.6$ & 0.38 \\
\hline Female Sex $(\mathrm{N})$ & $9(30.0)$ & $12(40.0)$ & $0.59^{*}$ \\
\hline Beta-blockers (N) & $18(60.0)$ & $16(53.3)$ & $0.80^{*}$ \\
\hline Ca-antagonists $(\mathrm{N})$ & $14(46.7)$ & $11(36.7)$ & $0.60^{*}$ \\
\hline Ace-inhibitors (N) & $7(23.3)$ & $5(16.7)$ & $0.75^{*}$ \\
\hline No cardiac medication $(\mathrm{N})$ & $5(16.7)$ & $8(26.7)$ & $0.53^{*}$ \\
\hline $\begin{array}{l}\text { AVR/CABG/ } \\
\text { ABG+AVR(N) }\end{array}$ & $8 / 11 / 11$ & $10 / 11 / 9$ & $0.81^{*}$ \\
\hline \multicolumn{4}{|c|}{ Preoperative echocardiographic imaging } \\
\hline Cardiac Index $\left(\mathrm{L} / \mathrm{min} / \mathrm{m}^{2}\right)$ & $2.34(2.04-2.79)$ & $2.25(2.02-2.88)$ & $0.85^{*}$ \\
\hline $\begin{array}{l}\text { Stroke Volume Index } \\
\left(\mathrm{ml} / \text { beat } / \mathrm{m}^{2}\right)\end{array}$ & $36(32-40)$ & $34(30-42)$ & $0.89^{*}$ \\
\hline Ejection Fraction (\%) & $47 \pm 7$ & $52 \pm 11$ & 0.11 \\
\hline $\begin{array}{l}\text { Global longitudinal peak } \\
\text { systolic strain (\%) }\end{array}$ & $14.7 \pm 3.4$ & $13.5 \pm 3.6$ & 0.28 \\
\hline \multicolumn{4}{|l|}{ Per-operative variables } \\
\hline Anaesthesia time (min) & $242 \pm 35$ & $251 \pm 51$ & 0.41 \\
\hline Operations time (min) & $168 \pm 34$ & $175 \pm 44$ & 0.48 \\
\hline Cross clamp time (min) & $56 \pm 23$ & $57 \pm 29$ & 0.88 \\
\hline $\begin{array}{l}\text { Cardiopulmonary bypass } \\
\text { time (min) }\end{array}$ & $87 \pm 26$ & $90 \pm 33$ & 0.62 \\
\hline
\end{tabular}

\# Categorical data $=$ No (\%), $\chi 2$-test; $\left.{ }^{*}\right)$ Non-parametric data $=$ median (interquartile range), Mann-Whitney test; All other data $=$ mean \pm SD, Independent samples T-test. EuroSCORE according to www.euroscore.org definitions. AVR=aortic valve replacement, $\mathrm{CABG}=$ coronary artery bypass grafting. Net anaesthesia time $=$ anaesthesia time minus operation time.

observation time from 48 hours to 72 hours. CPB in cardiac surgery normally is associated with moderate to severe haemodilution, which may results in delayed changes and we choose to evaluate serum creatinine changes primarily within 72 hours after surgery. The AKIN consensus is based on acute alterations in serum creatinine or urine output, taking into account the accumulating evidence that even small increments in serum creatinine are associated with adverse outcomes.

\section{Statistical analysis}

Comparisons between groups were evaluated using independent samples t-test for parametric data and the Mann-Whitney test for non-parametric data together with one- or two-way ANOVA for repeated measurements where
Table 2. The relative postoperative changes day by day in s-creatinine values compared to pre-operative s-creatinine divided on HTEA or control group together with maximal changes in the observation period.

\begin{tabular}{lll}
\hline & Control & HTEA \\
\hline Day 0 & $-2.5(-7-1)$ & $-4(-9-3)$ \\
Day 1 & $-3.5(-8-7)$ & $-3(-14-5)$ \\
Day 2 & $6(-6-24)$ & $-3(-13-9)$ \\
Day 3 & $3.5(-4-22)$ & $-3(-10-4)$ \\
Day 4 & $-2.5(-11-27)$ & $-2(-7-9)$ \\
Day 5 & $-2(-8-17)$ & $4(-1-11)$ \\
Day 6 & $4(-4-13)$ & $-2.5(-11-19)$ \\
Maximal & $14(2-31)$ & $6(-2-17)$ \\
\hline
\end{tabular}

appropriate. Categorical variables were evaluated with $\mathrm{x} 2$-test. Odds-ratio calculationwas performedwitha logistic regression model. Data in tables are reported as mean \pm standard deviation, median (interquartile range) or in percentages. A $p<0.05$ was considered significant for all the statistical tests. Statistic calculations were performed using the MedCalc ${ }^{\circledR}$ software version 12.5.0 (Mariakerke, Belgium).

\section{Results}

Patient groups were comparable concerning preoperative demographics, cardiac function evaluated by echocardiography and peroperative time data except for doses of Sufentanil (Table 1). One patient in the HTEA group did not receive a functional epidural, but as the protocol was based on intention to treat this patient was analysed in the HTEA group. No differences were found between groups in either s-creatinine or creatinine clearance calculated by the Cockroft-Gault formula [14].

The postoperative function of the epidural catheter was not tested. However, only $5(16.7 \%)$ had a postoperative need for morphine between 11 and $25 \mathrm{mg}$, while $13(43.3 \%)$ received between 1 and $10 \mathrm{mg}$ and 12 (40.0\%), compared to $100 \%$ in the control group receiving postoperative morphine.

The relatively changes in s-creatinine are given in (Table 2) and (Figure 1). Patients in the HTEA group showed statistical significant less increase in s-creatinine the first 3 postoperative days. (Figure 1a), while no differences was found in the later postoperative period (Figure $\mathbf{1 b}$ ). The number of patients developing acute kidney injury was lower in the HTEA group $4(13 \%)$ vs. control group 11 (37\%), but not statistically significant $(P=0.072)$.

Cardiopulmonary bypass (CPB) time was longer in patients developing AKI ( $104 \pm 23$ vs. $83 \pm 30 \mathrm{~min} ; P=0.022$, independent samples t-tests). In patients with CPB longer than 120 minutes there was no difference in the frequency of AKI, but in procedures with CBP shorter than 120 minutes the frequency in postoperative AKI was significant lower in HTEA patients (4.3\% vs. $33.3 \% ; P=0,0279 \times 2$-test). Patient subjected to double procedure (CABG+AVR) developed AKI more often $(50 \%$ vs. $14 \% ; P=0.004, X 2$-test). Further eight of the ten patients 

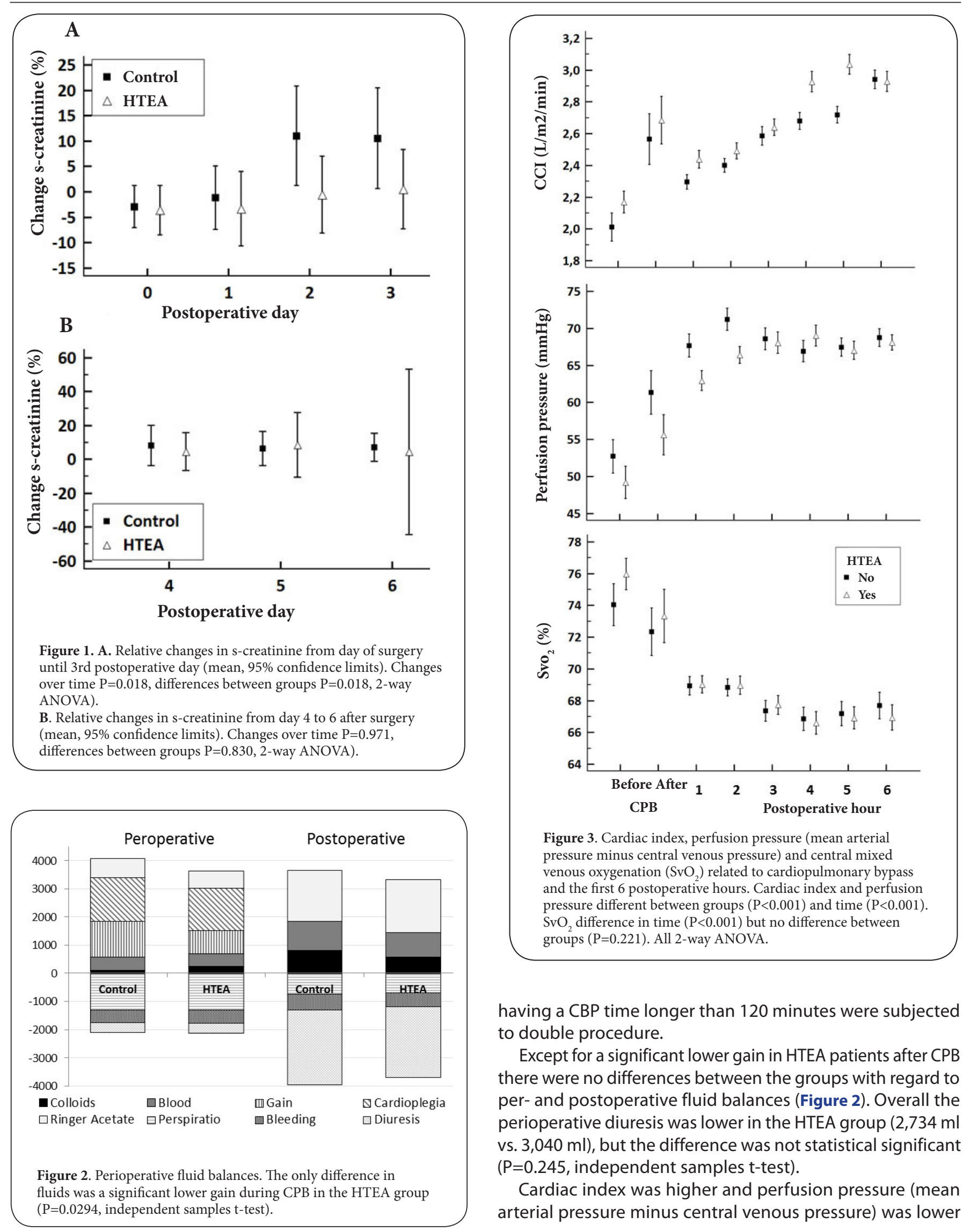

having a CBP time longer than 120 minutes were subjected to double procedure.

Except for a significant lower gain in HTEA patients after CPB there were no differences between the groups with regard to per- and postoperative fluid balances (Figure 2). Overall the perioperative diuresis was lower in the HTEA group $(2,734 \mathrm{ml}$ vs. $3,040 \mathrm{ml}$ ), but the difference was not statistical significant ( $P=0.245$, independent samples t-test).

Cardiac index was higher and perfusion pressure (mean arterial pressure minus central venous pressure) was lower 


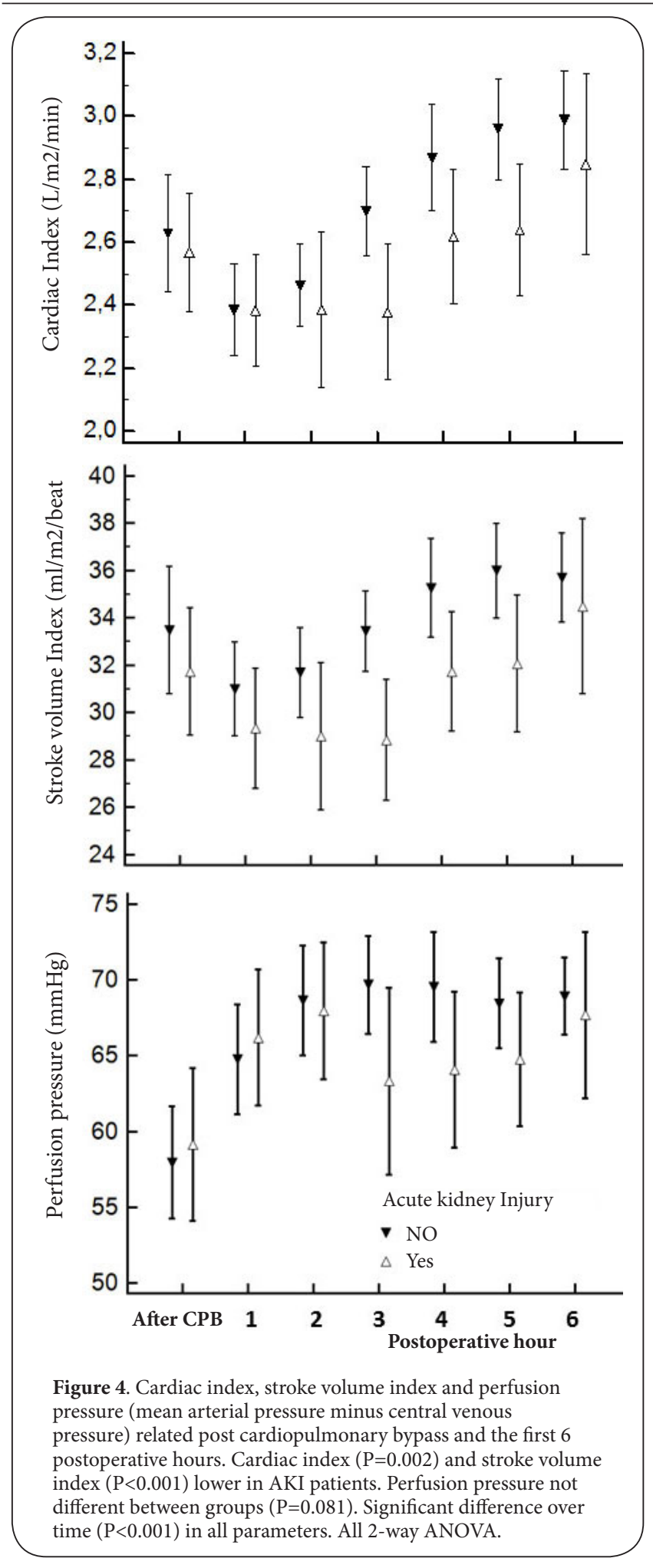

(Figure 3) in HTEA group. Accordingly systemic vascular resistance index was lower in HTEA group during surgery and the first six postoperative hours. No difference was found in heart rate, central venous pressure, peripheral saturation or
Table 3. Perioperative medical support divided on treatment groups. Overall the use of constrictors and vasodilators was statistical significant different $(\mathrm{P}=\mathbf{0 . 0 1 5 4}, \chi 2$-test). Individual test=Fisher's exact test.

\begin{tabular}{lccc}
\hline Perioperative medical support & Control & HTEA & p-value \\
\hline None & 3 & 2 & 1.0 \\
Inotropes & 4 & 2 & 0.67 \\
Constrictors & 5 & 17 & $<0.01$ \\
Dilatators & 18 & 9 & 0.04 \\
All patients & 30 & 30 & -- \\
\hline
\end{tabular}

Table 4. Odds-ratios (OR) and $95 \%$ confidence limits (95\% CI) of selected parameters for developing postoperative acute kidney injury.

\begin{tabular}{lc}
\hline Parameter & OR $(\mathbf{9 5 \%}$ CI $)$ \\
\hline Constrictors & $2.02(0.83-4.91)$ \\
Dilatators & $1.19(0.84-1.68)$ \\
CPB time $>120$ min. & $6.38(0.79-51.6)$ \\
Double procedure & $2.79(0.62-12.5)$ \\
Epidural & $0.10(0.01-0.67)$ \\
\hline
\end{tabular}

$\mathrm{SvO}_{2}$ between the groups.

Patients developing acute kidney injury had lower postoperative cardiac index $(\mathrm{P}=0.002)$ and lower stroke volume index $(\mathrm{P}<0.001)$, while all other parameters, including perfusion pressure $(\mathrm{P}=0.081)$, were not different (Figure 4).

Patients developing AKI had a higher overall perioperative fluid balance $(2,387 \mathrm{ml}$ vs. $1,296 \mathrm{ml}, \mathrm{P}=0.003$; Independent samples t-test). Approximately $60 \%$ of the fluid balance was added peroperatively, and was primarily due to a higher crystalloid infusion (2,624 ml vs. $2,043 \mathrm{ml} ; \mathrm{P}=0.002$, Independent samples t-test), while no statistical significant difference was found in colloid infusion $(288 \mathrm{ml}$ vs. $190 \mathrm{ml}$; $\mathrm{P}=0.258$ ).

Patients in HTEA group received more often perioperative Noradrenalin infusion ( $P=0.003)$, while patients in the control group more often was given vasodilators (primarily Nitroprusside; $\mathrm{P}=0.037 ;$ Table 3 ). A regression analysis of factors associated with the impact of developing postoperative AKI revealed that double procedure increased the risk while HTEA decreased the risk of postoperative AKI. (Table 4).

There was no difference in severe postoperative complications. In the control group one patient (3.3\%) died within 30 days and one patient (3.3\%) had postoperative myocardial infarction judged by new Q-wave. In the HTEA group one patient (3.3\%) suffered cerebral transitory ischaemic attack lasting less than 24 hours.

\section{Discussion}

The major finding in this study was the less increase in s-creatinine in HTEA patients in the first 72 hours after surgery. The fact that there were no differences in relative creatinine 
Greisen et al. Cardiovascular System 2013,

http://www.hoajonline.com/journals/pdf/2052-4358-1-11.pdf

doi: $10.7243 / 2052-4358-1-11$

changes after day 2-3, the time of removal of epidural catheter, may suggest that HTEA plays a role in the finding.

The overall number of patients developing acute kidney injury was $25 \%$ which is in accordance with a previous published study [15]. The above finding is further supported by the lower, although not significant number of patients developing acute kidney injury in the HTEA group and the significant lower odds-ratio demonstrated in (Table 3). It is well known that AKI after cardiac surgery is associated with short term complications as prolonged ventilation, postoperative length of stay and increased mortality [16]. Further, a recent study among 29,388 cardiac surgery patients suggests that even minimal increases in creatinine levels are associated in a graded manner with a subsequent increase in the risk of incident chronic kidney disease (CKD), progression of the kidney disease and mortality [17]. Patients with postoperative increases in creatinine up to $24 \%$ from baseline levels had an adjusted hazard ratio (HR) of 2.1 over time in the incidence of CKD, and a HR of 2.5 for a progression of CKD. Therefore the finding in this study of less increase in s-creatinine and a tendency of less development of AKI is of interest at least in generating the hypothesis of HTEA protecting the kidney in cardiac surgery.

The mechanisms behind a possible kidney-protective action of HTEA are not known. In our recent study on matched cardiac patients with and without HTEA [11] we concluded based on haemodynamic observations from our randomised study [12] that whole-body flow (cardiac output) seems more important than perfusion pressure over the kidney, which is in line with studies on renal pathophysiology in AKI showing that systemic and localized impaired renal blood flow is a major etiological factor in the early phase as a result of increased sympathetic renal-nerve activity and levels of vaso-constrictive agents [18].

The length of cardiopulmonary bypass is well known to be associated with the risk of developing postoperative AKI. A meta-analysis of 9 studies including 12466 patients concluded that longer CPB times are associated with a higher overall mortality. In consistency with these findings the risk of developing AKI would be higher in patients going through a surgical double procedure due to the longer bypass time [19], which is supported by our findings that patient with CPB time longer than 120 minutes had higher incidence of AKI. Further an older study showed a lower risk of developing $A K I$ in patients undergoing $C A B G$ alone compared to valve procedures or combinations [20], which is in accordance with our findings where AKI was significantly higher $(P=0.006$; $\mathrm{X} 2$-test) in combined procedures (50.0\%) compared to aortic valve replacement (16.7\%) and CABG (10\%). This is further emphasisedby the fact, that double procedure was more important for developing AKI than length of cardiopulmonary bypass as demonstrated by odds-ratios in (Table 3 ).

Cardiopulmonary bypass induces a neuroendocrine response with a substantial rise in vasoactive hormones as epinephrine, norepinephrine and vasopressin. The net effect of these physiological changes is a reduction in renal blood flow and a concomitant reduction in GFR [21]. This catecholamine response to cardiac surgery was abolished by the addition of HTEA to GA [22-23] and may thus account for a potential renal protective effect. Besides the analgesic properties of HTEA, it is widely accepted that it also reduces sympathetic nerve activity and thereby influences function of vital organ systems [24]. Data are limited on the segmental distribution of a thoracic sympathetic block in humans and methodological problems limit objective assessments [25], but from an animal study in cats it was found that a segmental sympathetic block resulted in a compensatory increased sympathetic nerve activity in unblocked segments [26]. Further, animal studies on ischaemic situations with and without renal denervation have shown a beneficial effect on the excretory functions of water and electrolytes after denervation [27-28]. As we could not find any statistical significant differences in volume load and diuresis between HTEA and control patients the reason for postoperative higher creatinine clearance and lower increase in s-creatinine could be a higher excretion of creatinine in the HTEA patients. Anatomical studies on the origin of renal nerves are scarce but studies of Mitchell [29] found that renal nerves have widespread origins, extending from the superior thoracic splanchnic nerve through the lumbar sympathetic nerves to the hypogastric plexus surrounding the aortic bifurcation in the pre-sacral region. Therefore it might be hypothesisedthat a beneficial effect of HTEA on renal function is dependent on a relative high fraction of complete block of the before mentioned segments of sympathetic structures.

It is well know that norepinephrineincreases renal function in both humans [30] and animals [31] with severely reduced peripheral resistance like septicaemia, but in contrary other studies have shown that norepinephrinemay induce renal failure in dogs [32]. Although moderate to high norepinephrineinfusion may increase renal blood flow [33] there also seems to be some evidence that when normal circulatory controls existed in an otherwise unstressed circulation, noradrenaline infusion does not increase dynamic renal blood flow despite increasing arterial pressures [31]. Thus from a theoretical point of view treatment of the lower peripheral resistance followed HTEA with norepinephrinemight have positive impact on the renal blood flow and thus account for the lower frequency of AKI found in HTEA patients. However, as indicated by the odds-ratios in (Table 3), the impact of norepinephrinewould be negative showing a non-significant odds-ratio of 1.36, in contrary to the independent lower impact of HTEA of 0.14 .

\section{Limitations of the study}

The study holds a limited number of patients. However the study is randomised and contains enough patients to demonstrate findings between HTEA and non-HTEA patients. A meta-analysis has shown a number of risk factors for developing postoperative AKI like advanced age, more 
than 3 units of blood transfusions while on CPB, emergency surgery and the perioperative use of an intra-aortic balloon pump [34], but besides that $33 \%$ of patients was between 75 and 80 years old, none of these factors was actual in the present study.

It is well known that CPB is associated with moderate to severe haemodilution and the overall relatively lower s-creatinine in the first 2-3 postoperative days, found in our study, is mostly due to this effect. However, the differences between HTEA and control patients cannot be accredited this effect as the volume load was lower, although not significantly, in the HTEA group and following the significant lower increases in s-creatinine must be due to either a decrease in synthesis or a higher clearance of creatinine. As suggested above the HTEA might be responsible for the latter mechanism.

The function of the epidural catheter was not tested before or after surgery. However the low number of patients requiring postoperative morphine was low indicating a functioningepidural analgesia.

Use of HTEA in connection with cardiac surgery is mostly done in protocolled studies and in research and thus the total number is less than 50 cases per year. In thoracic patients we do $350-400$ cases per year. In the last 10 years no serious neurologic sequelae has been observed in cardiac or thoracic surgery patients.

\section{Conclusion}

HTEA as a supplement to general anaesthesia in cardiac surgery patients is followed by lower increase in s-creatinine in the first 72 hours after surgery and a tendency towards lower incidence of AKI. As deterioration of kidney function after cardiac surgery is related to increased morbidity and mortality the finding of a possibly kidney-protective effect of HTEA could be of clinical importance and warrants further investigation.

\section{Competing interests}

The author declares that he has no competing interests.

\section{Authors' contributions}

\begin{tabular}{|l|c|c|c|c|c|}
\hline Authors' contributions & JG & DVN & PKR & ES & CJJ \\
\hline Research concept and design & $\checkmark$ & - & - & -- & $\checkmark$ \\
\hline Collection and/or assembly of data & $\checkmark$ & -- & -- & -- & $\checkmark$ \\
\hline Data analysis and interpretation & $\checkmark$ & $\checkmark$ & $\checkmark$ & $\checkmark$ & $\checkmark$ \\
\hline Writing the article & $\checkmark$ & $\checkmark$ & $\checkmark$ & $\checkmark$ & $\checkmark$ \\
\hline Critical revision of the article & $\checkmark$ & $\checkmark$ & $\checkmark$ & $\checkmark$ & $\checkmark$ \\
\hline Final approval of article & $\checkmark$ & $\checkmark$ & $\checkmark$ & $\checkmark$ & $\checkmark$ \\
\hline Statistical analysis & -- & -- & -- & -- & $\checkmark$ \\
\hline
\end{tabular}

Publication history

EIC: William Clifford Roberts, Baylor University Medical Center, USA.

Received: 09-Aug-2013 Revised: 28-Aug-2013

Re-Revised: 21-Sep-2013 Accepted: 04-Oct-13

Published: 26-Oct-2013

\section{References}

1. van Mastrigt GA, Maessen JG, Heijmans J, Severens JL and Prins MH. Does fast-track treatment lead to a decrease of intensive care unit and hospital length of stay in coronary artery bypass patients? A metaregression of randomized clinical trials. Crit Care Med. 2006; 34:162434. | Article | PubMed

2. Myles PS and Mcllroy D. Fast-track cardiac anesthesia: choice of anesthetic agents and techniques. Semin Cardiothorac Vasc Anesth. 2005; 9:5-16. | Article | PubMed

3. Dowd NP, Karski JM, Cheng DC, Gajula S, Seneviratne P, Munro JA and Fiducia D. Fast-track cardiac anaesthesia in the elderly: effect of two different anaesthetic techniques on mental recovery. Br J Anaesth. 2001; 86:68-76. | Article | PubMed

4. Engoren $\mathrm{M}$, Luther $\mathrm{G}$ and Fenn-Buderer N. A comparison of fentanyl, sufentanil, and remifentanil for fast-track cardiac anesthesia. Anesth Analg. 2001; 93:859-64. | Article | PubMed

5. Tritapepe L, Voci P, Di Giovanni C, Pizzuto F, Cuscianna E, Caretta Q and Pietropaoli P. Alfentanil and sufentanil in fast-track anesthesia for coronary artery bypass graft surgery. J Cardiothorac Vasc Anesth. 2002; 16:157-62. | Article | PubMed

6. Cheng DC, Wall C, Djaiani G, Peragallo RA, Carroll J, Li C and Naylor D. Randomized assessment of resource use in fast-track cardiac surgery 1-year after hospital discharge. Anesthesiology. 2003; 98:651-7. | Article I PubMed

7. Svircevic $V$, van Dijk D, Nierich AP, Passier MP, Kalkman CJ, van der Heijden GJ and Bax L. Meta-analysis of thoracic epidural anesthesia versus general anesthesia for cardiac surgery. Anesthesiology. 2011; 114:271-82. | Article | PubMed

8. Bignami E, Landoni G, Biondi-Zoccai GG, Boroli F, Messina M, Dedola E, Nobile L, Buratti L, Sheiban I and Zangrillo A. Epidural analgesia improves outcome in cardiac surgery: a meta-analysis of randomized controlled trials. J Cardiothorac Vasc Anesth. 2010; 24:586-97. | Article I PubMed

9. Caputo M, Alwair H, Rogers CA, Pike K, Cohen A, Monk C, Tomkins S, Ryder I, Moscariello C, Lucchetti V and Angelini GD. Thoracic epidural anesthesia improves early outcomes in patients undergoing off-pump coronary artery bypass surgery: a prospective, randomized, controlled trial. Anesthesiology. 2011; 114:380-90. | Article | PubMed

10. Svircevic V, Nierich AP, Moons KG, Diephuis JC, Ennema JJ, Brandon Bravo Bruinsma GJ, Kalkman CJ and van Dijk D. Thoracic epidural anesthesia for cardiac surgery: a randomized trial. Anesthesiology. 2011; 114:262-70. | Article | PubMed

11. Stenger M, Fabrin A, Schmidt H, Greisen J, Erik Mortensen P and Jakobsen CJ. High Thoracic Epidural Analgesia as an Adjunct to General Anesthesia is Associated with Better Outcome in Low-to-Moderate Risk Cardiac Surgery Patients. J Cardiothorac Vasc Anesth. 2013; 27:e35. | Article I PubMed

12. a. Jakobsen CJ, Bhavsar R, Nielsen DV, Ryhammer PK, Sloth E and Greisen J. High thoracic epidural analgesia in cardiac surgery. Part 1--high thoracic epidural analgesia improves cardiac performance in cardiac surgery patients. J Cardiothorac Vasc Anesth. 2012; 26:1039-47. I Article I PubMed

b. Nielsen DV, Bhavsar R, Greisen J, Ryhammer PK, Sloth E and Jakobsen CJ. High thoracic epidural analgesia in cardiac surgery. Part 2--high thoracic epidural analgesia does not reduce time in or improve quality of recovery in the intensive care unit. J Cardiothorac Vasc Anesth. 2012; 26:1048-54. | Article | PubMed

13. Mehta RL, Kellum JA, Shah SV, Molitoris BA, Ronco C, Warnock DG and Levin A. Acute Kidney Injury Network: report of an initiative to improve outcomes in acute kidney injury. Crit Care. 2007; 11:R31. | Article | PubMed Abstract | PubMed Full Text

14. Cockcroft DW and Gault MH. Prediction of creatinine clearance from serum creatinine. Nephron. 1976; 16:31-41. | Article | PubMed

15. Nielsen DV, Hjortdal V, Larsson $\mathrm{H}$, Johnsen SP and Jakobsen CJ. Perioperative aminoglycoside treatment is associated with a higher incidence of postoperative dialysis in adult cardiac surgery patients. $J$ 
Greisen et al. Cardiovascular System 2013,

http://www.hoajonline.com/journals/pdf/2052-4358-1-11.pdf

Thorac Cardiovasc Surg. 2011; 142:656-61. | Article | PubMed

16. Mehta RH, Honeycutt E, Patel UD, Lopes RD, Shaw LK, Glower DD, Harrington RA, Califf RM and Sketch MH, Jr. Impact of recovery of renal function on long-term mortality after coronary artery bypass grafting. Am J Cardiol. 2010; 106:1728-34. | Article | PubMed

17. Ishani A, Nelson D, Clothier B, Schult T, Nugent S, Greer N, Slinin Y and Ensrud KE. The magnitude of acute serum creatinine increase after cardiac surgery and the risk of chronic kidney disease, progression of kidney disease, and death. Arch Intern Med. 2011; 171:226-33. | Article I PubMed

18. Bonventre JV. Pathophysiology of acute kidney injury. Nephrology rounds. 2008; 6.

19. Kumar AB, Suneja M, Bayman EO, Weide GD and Tarasi M. Association between postoperative acute kidney injury and duration of cardiopulmonary bypass: a meta-analysis. J Cardiothorac Vasc Anesth. 2012; 26:64-9. | Article | PubMed

20. Chertow GM, Lazarus JM, Christiansen CL, Cook EF, Hammermeister KE, Grover F and Daley J. Preoperative renal risk stratification. Circulation. 1997; 95:878-84. | Article | PubMed

21. Bellomo R, Auriemma S, Fabbri A, D'Onofrio A, Katz N, McCullough PA, Ricci Z, Shaw A and Ronco C. The pathophysiology of cardiac surgeryassociated acute kidney injury (CSA-AKI). Int J Artif Organs. 2008; 31:166-78. | PubMed

22. Moore CM, Cross MH, Desborough JP, Burrin JM, Macdonald IA and Hall GM. Hormonal effects of thoracic extradural analgesia for cardiac surgery. Br J Anaesth. 1995; 75:387-93. | Article | PubMed

23. Stenseth R, Bjella L, Berg EM, Christensen O, Levang OW and Gisvold SE. Thoracic epidural analgesia in aortocoronary bypass surgery. II: Effects on the endocrine metabolic response. Acta Anaesthesiol Scand. 1994; 38:834-9. | Article | PubMed

24. Clemente $A$ and Carli $F$. The physiological effects of thoracic epidural anesthesia and analgesia on the cardiovascular, respiratory and gastrointestinal systems. Minerva Anestesiol. 2008; 74:549-63. | PubMed

25. Freise $\mathrm{H}$ and Van Aken HK. Risks and benefits of thoracic epidural anaesthesia. Br J Anaesth. 2011; 107:859-68. | Article | PubMed

26. Taniguchi M, Kasaba T and Takasaki M. Epidural anesthesia enhances sympathetic nerve activity in the unanesthetized segments in cats. Anesth Analg. 1997; 84:391-7. I Article | PubMed

27. Salman IM, Ameer OZ, Sattar MA, Abdullah NA, Yam MF, Najim HS, $\mathrm{Khan} \mathrm{AH}$ and Johns EJ. Role of the renal sympathetic nervous system in mediating renal ischaemic injury-induced reductions in renal haemodynamic and excretory functions. Pathology. 2010; 42:259-66. Article | PubMed

28. Malpas SC, Shweta A, Anderson WP and Head GA. Functional response to graded increases in renal nerve activity during hypoxia in conscious rabbits. Am J Physiol. 1996; 271:R1489-99. | PubMed

29. Mitchell GA. The nerve supply of the kidneys. Acta Anat (Basel). 1950; 10:1-37. | Article | PubMed

30. Redl-Wenzl EM, Armbruster C, Edelmann G, Fischl E, Kolacny M, Wechsler-Fordos A and Sporn P. The effects of norepinephrine on hemodynamics and renal function in severe septic shock states. Intensive Care Med. 1993; 19:151-4. | Article | PubMed

31. Bellomo R, Kellum JA, Wisniewski SR and Pinsky MR. Effects of norepinephrine on the renal vasculature in normal and endotoxemic dogs. Am J Respir Crit Care Med. 1999; 159:1186-92. | Article | PubMed

32. Cronin RE, Erickson AM, de Torrente A, McDonald KM and Schrier RW. Norepinephrine-induced acute renal failure: a reversible ischemic model of acute renal failure. Kidney Int. 1978; 14:187-90. | Article | PubMed

33. Anderson WP, Korner PI and Selig SE. Mechanisms involved in the renal responses to intravenous and renal artery infusions of noradrenaline in conscious dogs. J Physiol. 1981; 321:21-30. | Website | PubMed Abstract I PubMed Full Text

34. Mangano CM, Diamondstone LS, Ramsay JG, Aggarwal A, Herskowitz A and Mangano DT. Renal dysfunction after myocardial revascularization: risk factors, adverse outcomes, and hospital resource utilization. The Multicenter Study of Perioperative Ischemia Research Group. Ann Intern Med. 1998; 128:194-203. | Article | PubMed

\section{Citation:}

Greisen J, Nielsen DV, Ryhammer PK, Sloth E and Jakobsen C-J. High thoracic epidural analgesia supplement seems to protect renal function, evaluated by serum creatinine changes, in cardiac surgery patients - a randomised study. Cardio Vasc Syst. 2013; 1:11. http://dx.doi.org/10.7243/2052-4358-1-11 